\title{
Biochemical Determinants of Growth Sparing during Neonatal Nutritional Deprivation or Enhancement: Ornithine Decarboxylase, Polyamines, and Macromolecules in Brain Regions and Heart
}

\author{
J. M. BELL, W. L. WHITMORE, K. L. QUEEN, L. ORBAND-MILLER, AND T. A. SLOTKIN \\ Department of Pharmacology, Duke University Medical Center, Durham. North Carolina 27710
}

\begin{abstract}
In order to elucidate the biochemical mechanisms operating to protect the brain from growth retardation in response to nutritional deprivation, comparisons were made of markers of cellular development in brain regions (cerebellum, cerebral cortex, midbrain + brainstem) and in a tissue which is not spared (heart). Nutritional status of neonatal rats was manipulated by increasing or decreasing the litter size beginning at birth, and development of DNA, RNA, and proteins followed throughout the neonatal period. In addition, we assessed the activity and levels of ornithine decarboxylase and its metabolic products, the polyamines, which are known to coordinate macromolecule synthesis in immature tissue and to provide an early index of perturbed development. Cardiac ornithine decarboxylase and polyamines were altered within $48 \mathrm{~h}$ of initiating the changes in litter size, and the direction and magnitude of these biochemical effects were predictive of subsequent impairment or enhancement of organ growth and of cellular development. All three brain regions were buffered from growth alterations relative to the heart, but the cerebellum, which undergoes major phases of cell replication later than the other two regions, was somewhat less protected. The spared brain regions also showed evidence of compensatory hypertrophy in nutritional deprivation (increased protein/DNA ratio) which accounts for maintenance of growth in the presence of reduced cell numbers. Thus, brain growth sparing involves specific cellular responses which are dependent on the maturational profile of each brain region. (Pediatr Res 22:599-604, 1987)
\end{abstract}

\section{Abbreviations}

ODC, ornithine decarboxylase ANOVA, analysis of variance

The growth and development of the neonate are controlled, in large part, by nutritional status (1-3). Nevertheless, the developing nervous system is spared relative to the rest of the body, and although nutritionally induced reductions of brain size and cell number can be produced, these are generally of far smaller magnitude than those seen in nonneural tissues (1-3). Within the brain, a hierarchy of susceptibility to altered growth has been

Received March 16, 1987; accepted July 9, 1987.

Correspondence Dr. J. M. Bell, Box 3813, Duke University Medical Center, Durham, NC 27710.

Supported by USPHS HD-09713. demonstrated, which depends primarily upon the maturational timetables for cellular replication and differentiation (1-3). The question remains, however, as to the mechanisms by which brain growth sparing occurs. Recent evidence has demonstrated that macromolecule synthesis during cellular replication is controlled through the ODC/polyamine pathway (4-6), and that early measurements of ODC activity and/or levels of the polyamines can predict subsequent toxicological or nutritional alterations of cellular maturation (6-11). In the current study, we have examined the biochemical basis of brain sparing through measurements of ODC, polyamines and macromolecules in brain regions and in a nonneuronal tissue whose growth is not spared (heart). The heart provides an excellent model for comparison with the brain because, like neuronal tissues, it ceases cellular replication in the early postnatal period, and because its timetable for replication and differentiation resembles that of the cerebellum (7, 11-13). In altering neonatal nutrition, we have adopted a commonly used model, namely increasing or decreasing litter size; this has the advantage of leaving maternal nutrition unaffected as well as maintaining constant contact of the pups with their dam $(1,14)$. With regard to the latter factor, recent work has shown that removing pups from the dam produces growth retardation which is independent of nutrition and which resembles psychosocial dwarfism $(15,16)$, and therefore the manipulation of litter size would appear to give a more definable model of malnutrition or overnutrition. Our results are consistent with the view that the response of developing tissues to nutritional alterations is determined by early regulatory changes in the ODC/ polyamine system which are distinctly different in neuronal versus nonneuronal tissues.

\section{METHODS}

Eighty primiparous Sprague-Dawley rats (Zivic-Miller Laboratories, Allison Park, PA) were shipped by climate-controlled truck 2 wk prior to parturition and were placed on Purina rat chow ad libitum. Immediately after birth, pups from all litters were randomized and redistributed into three litter size categories: five to six pups (small litter), 10-11 pups (standard litter), or 16-17 pups (large litter). As pups were chosen for each experiment, randomization within each category was carried out again in order to maintain the respective litter sizes. Animals of both sexes were randomly selected from different cages on each experiment day and groups were always sex matched. Pups were killed by decapitation and hearts were removed, drained of blood, and weighed. Brains were dissected into cerebellum, cerebral cortex and midbrain + brainstem as described previously (20). Analysis of ODC activity, nucleic acids, proteins and polyamines were carried out by standard procedures $(11,17-25)$. 
Statistics. Data are reported as means and SEs. Statistical comparisons were first made by a global ANOVA for each type of measurement, with separation of factors by age, tissue, and litter size. Where a significant interaction of litter size $\times$ tissue or litter size $\times$ tissue $\times$ age was found, a separate two-way ANOVA was conducted for each tissue in order to typify the litter size effect. Significance was defined as $p<0.05$.

\section{RESULTS}

Body and tissue growth. Manipulation of nutritional status via altering the litter size produced a highly significant shift in growth rates of neonatal rats (Fig. 1). Normal growth was maintained for the first few days after the pups were distributed into the three categories. However, abnormal body weights became apparent in the nutritionally deprived and nutritionally enhanced groups starting at the end of the 1st postnatal wk and the effects intensified thereafter. By the middle or end of the $3 \mathrm{rd} \mathrm{wk}$, weight differences of as much as $40 \%$ were found. These actions were also reflected in effects on heart growth. Although brain region weights were also statistically significantly affected by litter size manipulation, sparing was evident in that the deficits in the deprived group were of much smaller magnitude. There was also a hierarchy of growth-retardant effects in the three brain regions with the largest effect seen in the cerebellum. Notably, nutritional enhancement did not alter brain growth.

$O D C$ activity and polyamine levels. Measurements of ODC activity were conducted for two purposes. First, because ODC has an extremely short turnover time and is responsive to the maternal caretaking environment, acute $(\mathrm{h})$ reductions in activity are readily seen if caretaking is adversely affected $(15,16,26)$. We found normal ODC activities $12 \mathrm{~h}$ after redistribution of the pups to the various litter sizes (data not shown), and it is thus likely that the subsequent changes in growth, ODC, polyamines, and macromolecules reflect nutritional variables. Measurement of long-term changes in ODC activity (days) has been used to detect and predict growth-related alterations in cellular maturation (4-10, 23-26). In the current study, the litter-size manipulations were associated with shifts in the cardiac ODC developmental pattern consistent with subsequent growth impairment in the nutritionally deprived group, namely an initial inhibition of activity, followed by rebound elevations (Fig. 2). On the other hand, overnutrition (small litter size) was associated with an ODC pattern typifying enhanced growth, namely an initial elevation of activity. These changes all preceded by several days the effects of litter size manipulation on cardiac growth. The effects on heart ODC were distinctly different from those on brain ODC, where nutritional alterations had little or no consistent effect.

Alterations of litter size had significant effects on polyamine levels in developing tissues (Fig. 3). The prominent cardiac growth retardation or enhancement was preceded by a disruption of the developmental patterns of spermidine and spermine which was apparent even at 2 days of age; this was characterized by deficits in the nutritionally enhanced (small litter size) animals and elevations in the nutritionally deprived (large litter size) group. In the cerebella of the growth-impaired animals, significant overall elevations were seen in putrescine, spermidine, and spermine, but there was little or no effect on polyamines in overnourished pups. The other two brain regions (cerebral cortex, midbrain + brainstem) did not show any alterations of putrescine, spermidine or spermine which were consistent with the differential growth rates in the enhanced or deprived groups.

Macromolecules. DNA content of developing cardiac tissue was drastically affected by both types of nutritional manipulations (Fig. 4). Although DNA remained within normal bounds through the end of the 1st postnatal wk, by 10 days of age significant enhancement was evident in the overnourished ani-
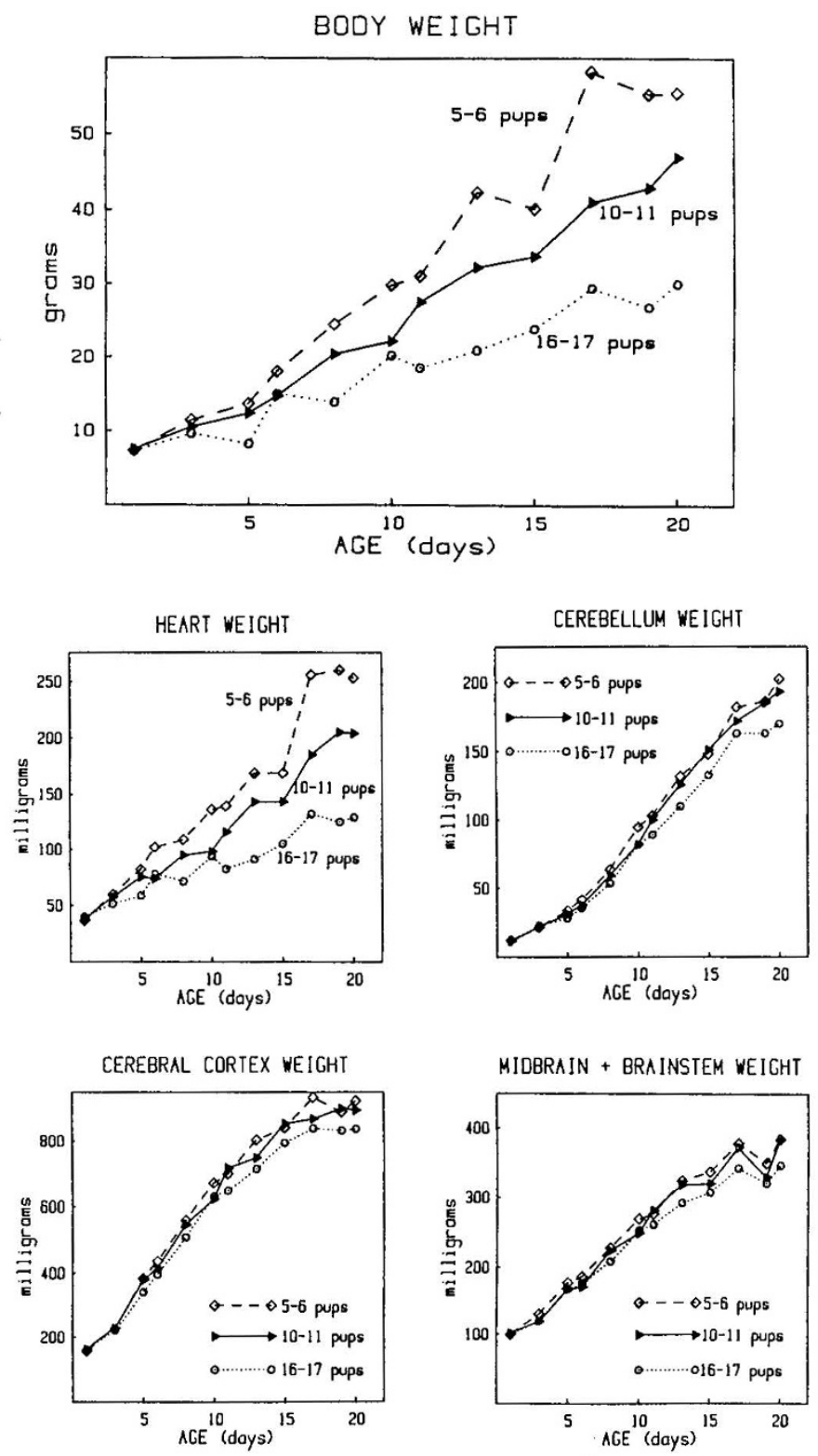

Fig. 1. Effects of litter size manipulation on development of body and tissue weights. Data represent mean values from at least eight animals selected from different litters in each group at each age. SEs were $<3 \%$. For body weight, two-way ANOVA indicates a main effect of litter size, as well as a litter size $\times$ age interaction. For tissue weights, three-way ANOVA indicates a significant main effect of litter size and a significant interaction of litter size by age. The effect was preferentially expressed in the individual tissues (significant litter size $\times$ tissue interaction) as follows: heart $>$ cerebellum $>$ cerebral cortex $>$ midbrain + brainstem. Two-way ANOVA indicates a significant litter size effect for each tissue as well as a significant litter size $\times$ age interaction in heart and cerebellum.

mals, and by 13 days the undernourished group became substantially subnormal. Cardiac RNA was influenced to a much smaller degree. In the cerebellum, a significant reduction (malnutrition) or enhancement (overnutrition) of DNA was also detectable from the 2nd postnatal wk onward, but the magnitude of effect was much smaller than that in the heart. Cerebellar RNA was not altered. A similar pattern was seen in the other two brain regions, with significant changes in DNA, but not RNA content; as was true for growth, there was a hierarchy of the litter-size effect on 

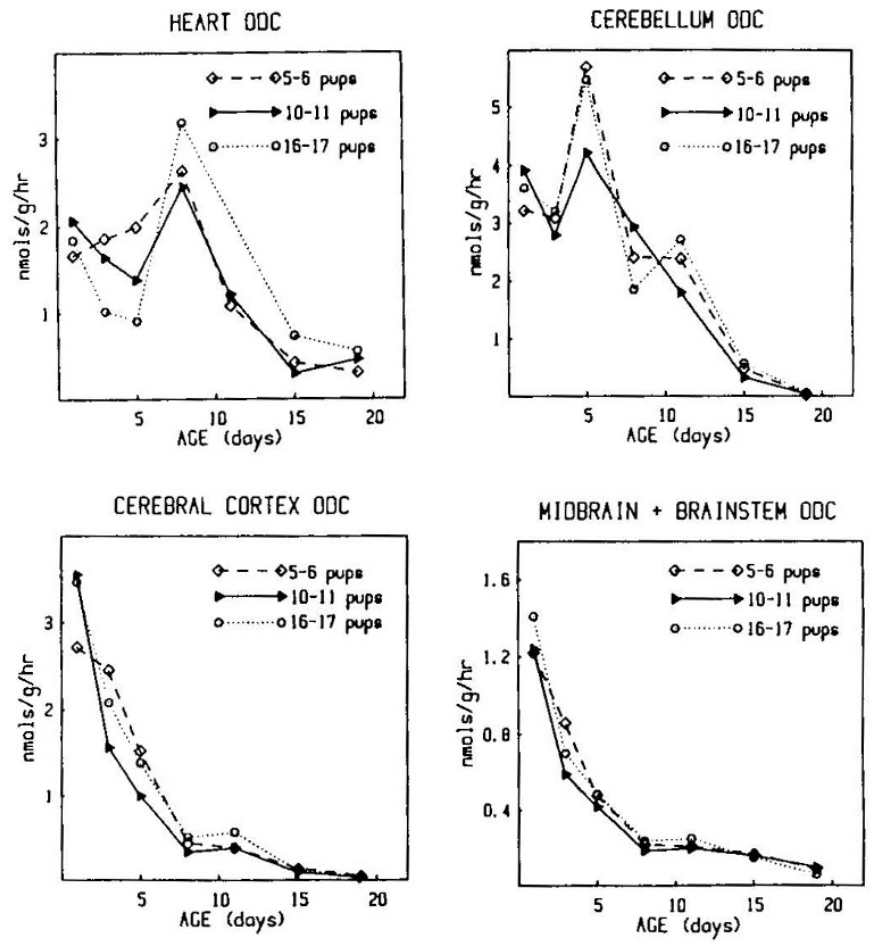

Fig. 2. Effect of litter size manipulation on development of heart and brain region ODC activity. Data represent mean values from at least eight animals selected from different litters in each group at each age. SEs were $<15 \%$. Three-way ANOVA indicates a significant main effect of litter size on ODC activity, which was interactive with age, and which was largely restricted to the heart (litter size $\times$ tissue interaction). Twoway ANOVA indicates a significant litter size $\times$ age interaction in the heart, but not in any of the three brain regions.

DNA, namely cerebellum $>$ cerebral cortex $>$ midbrain + brainstem.

Evaluations of protein content (Fig. 5) also indicated a significant impact of neonatal nutritional status on macromolecular development. Protein content was most severely affected in the heart, with deficits or enhancements comparable to the effects on tissue weight. However, protein per cell was affected only slightly, as shown by the cardiac protein/DNA ratio. Protein content was also altered in all brain regions, albeit to a lesser extent than in the heart. Protein/DNA ratios were only slightly affected in the cerebellum but exhibited major early elevations in cerebral cortex and midbrain + brainstem in the nutritionally deprived animals.

\section{DISCUSSION}

Previous studies have shown that rearing neonatal rats in groups ranging from large to small numbers of pups can respectively slow or enhance the rate of growth and cell acquisition in individual tissues $(1-3)$. The present study indicates that these changes are not distributed homogeneously. In a nonneural tissue, such as the heart, dietary restriction produced severe reductions in weight gain which appeared to reflect a primary deficit in acquisition of new cells. This was demonstrated by the profound retardation of age-dependent increases in cardiac DNA as opposed to other macromolecules; the relatively normal protein content per cell (protein/DNA) indicated that no compensatory hypertrophy occurred in reaction to the shortfall in cell number. Nutritional status appeared to act as a regulator of cardiac development in either direction, as enhancement of cell numbers without changes in relative cell size were readily ob- tained via overfeeding of the neonates (small than normal litter size).

A different spectrum of effects on macromolecular development was apparent in the brain, where growth sparing was prominent. In the regions most highly spared, midbrain + brainstem and cerebral cortex, there were much smaller changes in DNA and none in RNA. Furthermore, there was evidence for compensatory hypertrophy during the early phase, as shown by elevations in protein/DNA. In contrast, the effects of malnutrition in the cerebellum, a region in which cell replication occurs largely postnatally (as in the heart), were midway between those seen in the heart and those seen in the spared brain regions. The cerebellum showed intermediate shortfalls in cell number (DNA), sparing of RNA and no evidence of compensatory hypertrophy (protein/DNA). In the brain regions we were not able to detect an enhancement of growth or cellular development as a result of overnutrition. Thus, although brain tissue is inherently less susceptible to nutritional alterations, some vulnerability is evident if the insult occurs during the period of rapid cell replication, and in this case (cerebellum) the pattern bears some semblance to that seen in the heart.

The question remains as to why the impact of nutritional alterations on macromolecular development is expressed differently in the various tissues. One possibility is that intracellular regulators of macromolecule synthesis are not uniformly affected. In the current study, the alterations in cell acquisition and growth in the most vulnerable tissue, the heart, were preceded by a corresponding alteration in ODC. For growth retardation, this was characterized by early reductions and subsequent rebound elevations in enzyme activity, a pattern recognized as a characteristic of delayed development $(7-10,24)$. Cardiac growth enhancement, on the other hand, was preceded by elevations in ODC. The relative lack of effect of nutritional deprivation or enhancement on brain ODC can thus be taken as an early indicator of the subsequent sparing of both growth and macromolecule content. A similar pattern was found for nutritional effects on polyamine levels, namely a predominance of early actions on cardiac tissue and a lack of effect on the most highly spared brain regions. The cerebellum, where effects on growth and development were intermediate, did display alterations in polyamine levels, but the onset of the effects was later than in the heart. In fact, undernutrition led to changes in cerebellar polyamine levels centered around the 2 nd to 3 rd postnatal wk, a period in which granule cell replication and migration are occurring, along with axonogenesis and dendritic arborization $(13,27)$. It is of particular importance that maintenance of ODC activity is a requisite for these events in the developing cerebellum (27), and we have reported herein for the first time that the levels of spermidine and spermine reach a peak during this phase, a pattern unique to the cerebellum. It would thus be worthwhile to examine the impact of neonatal malnutrition on cerebellar architecture as distinct from gross measures of cell numbers.

It is of additional interest that nutritionally induced alterations in the most vulnerable tissue, the heart, are largely confined to spermidine and spermine, rather than the immediate product of the ODC reaction, putrescine. This suggests some dissociation between the activity of ODC itself and the accumulation of polyamines in the tissue. Indeed, in the cerebellum this can be seen even more prominently, because alterations in polyamine levels were detected in the absence of changes in ODC activity. Previous work with ODC inhibitors has suggested that significant polyamine accumulation can occur in the absence of ODC activity $(23,25)$, and some estimates of polyamine reutilization rates indicate that as little as $30 \%$ of brain putrescine originates directly from the decarboxylation of ornithine (28). Because brain tissue, in particular, contains active uptake mechanisms for putrescine and the polyamines $(29,30)$, acquisition of these compounds may be regulated separately from that of ODC during development. The question of whether similar mecha- 
PUTRESCINE
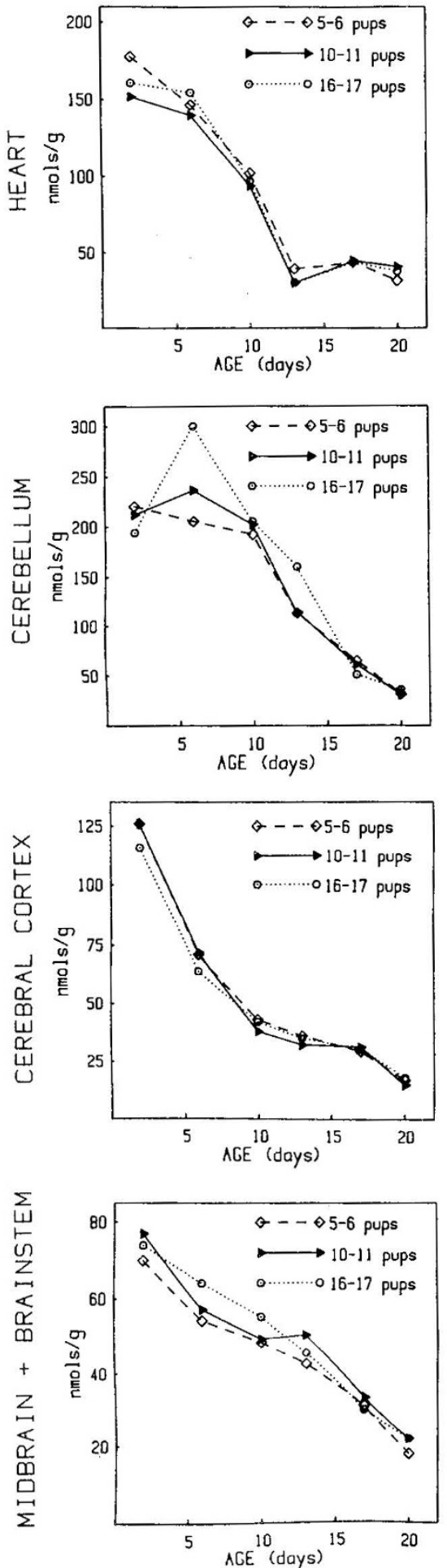

SPERMIDINE
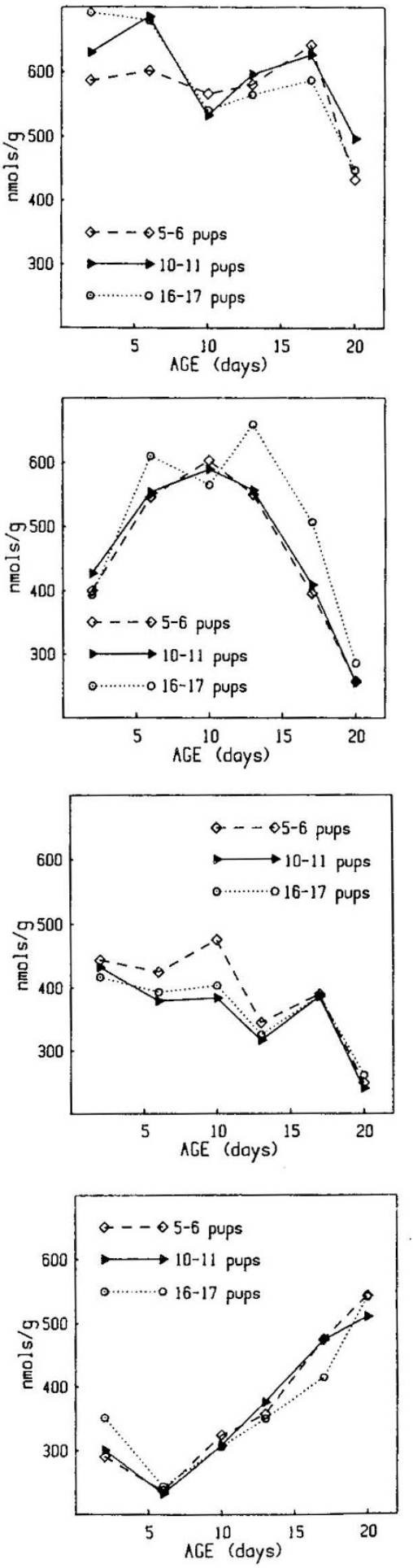

SPERMINE
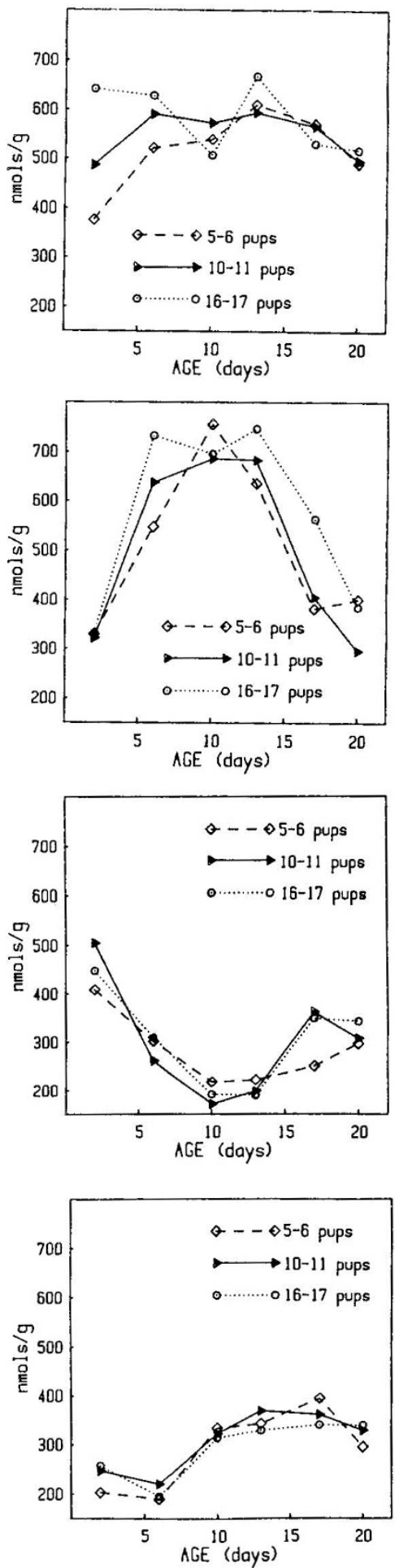

Fig. 3. Effect of litter size manipulation on development of tissue polyamine levels. Data represent mean values from at least eight animals selected from different litters in each group at each age. SEs were $<10 \%$. Global ANOVA indicates significant main effects of litter size and interactions with age and tissue for all polyamines. In the heart, three-way ANOVA indicates significant main effects of litter size and interactions with all other variables, with the largest effect on spermine (main effect and interaction with age). In the cerebellum, all main effects and interactions were significant for all three polyamines. In the cerebral cortex, a significant main effect was seen for spermidine and an interaction of litter size $\times$ age for spermine. In the midbrain + brainstem, there were no significant effects or interactions for any individual polyamine.

nisms operate in developing cardiac tissue has not yet been fully explored, but at least one study indicates a failure of chronic ODC inhibition to deplete spermidine and spermine (31).

Thus, it appears that brain sparing during nutritional depri- vation or enhancement is characterized by a relative resistance to the macromolecular changes which occur in the nonspared tissues. Because the primary effects are on cell acquisition, the cerebellum is the least spared, since it is undergoing rapid cell 

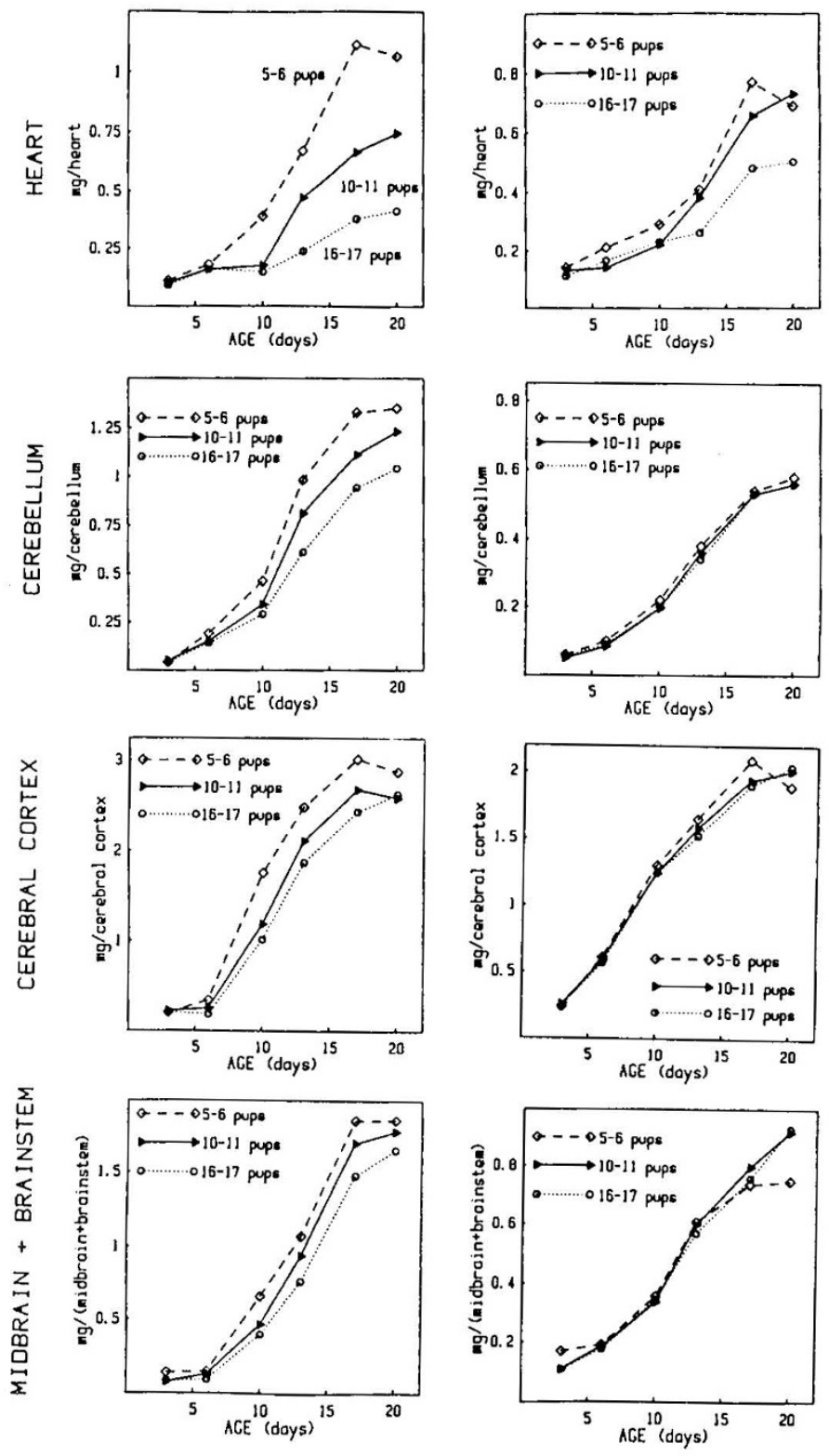

Fig. 4. Effect of litter size manipulation on development of tissue DNA and RNA levels. Data represent mean values from at least eight animals selected from different litters in each group at each age. SEs were $<6 \%$. For DNA, three-way ANOVA indicates a significant main effect of litter size and significant interactions of litter size with tissue and age; the interaction with tissue reflected preferential effects on heart $>$ cerebellum $>$ cerebral cortex $>$ midbrain + brainstem. Two-way ANOVA for DNA also indicates significant effects of litter size and interaction of litter size $\times$ age for each tissue. For RNA, three-way ANOVA indicates a significant effect of litter size which was preferential for the heart: only the heart showed a main effect of litter size as well as an interaction of litter size $\times$ age (two-way ANOVA). RNA in the three brain regions either indicated no effect or interaction (cerebellum) or only a small litter. size $\times$ age interaction (cerebral cortex, midbrain + brainstem).

replication during the phase of nutritional insult. Finally, it appears that the early alterations in the $\mathrm{ODC} /$ polyamine pathway are indeed predictive of growth sparing and may participate directly in the macromolecular adaptations which distinguish between spared and nonspared tissues.
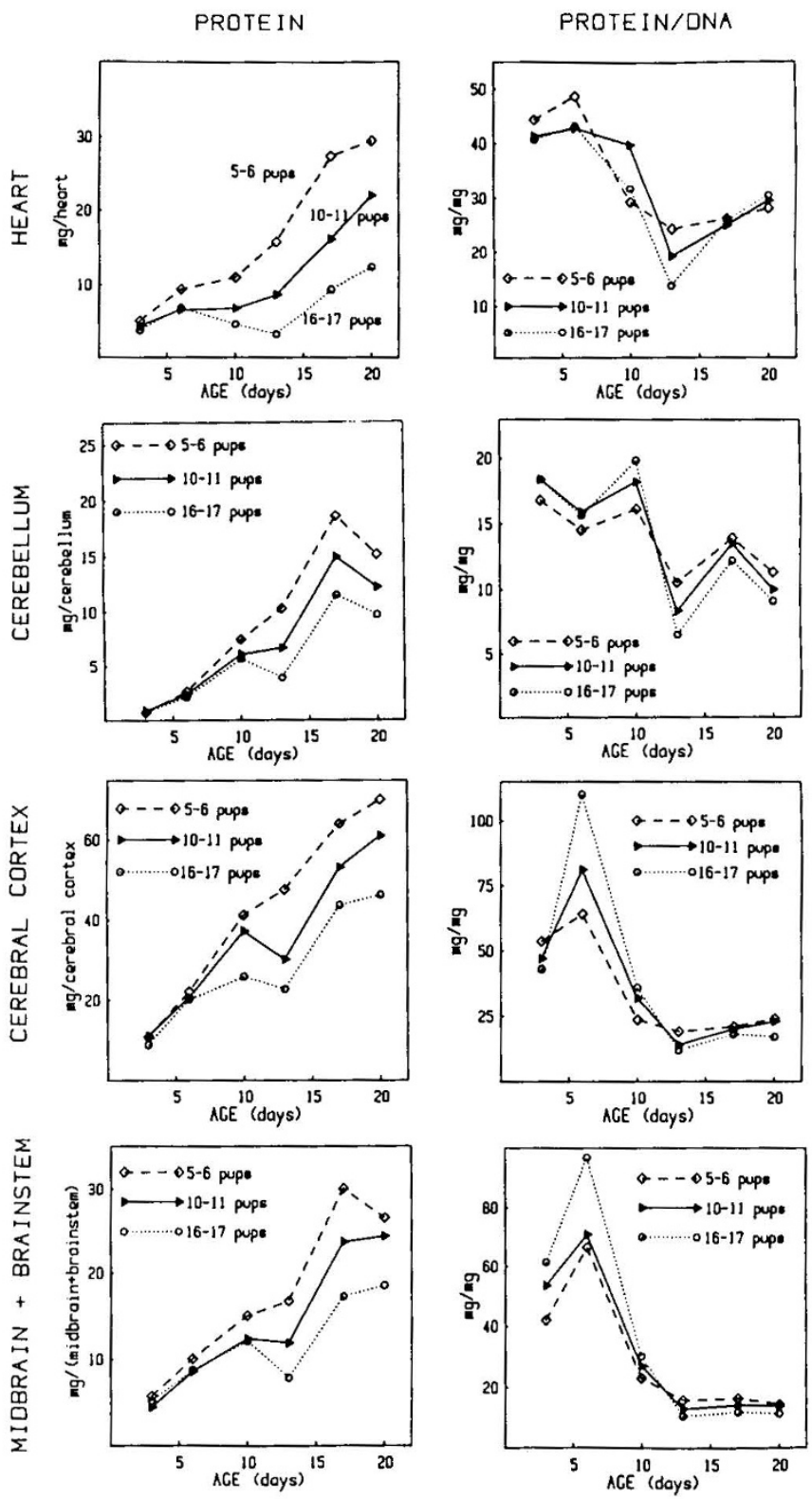

Fig. 5. Effects of litter size manipulation on development of tissue protein levels, expressed as content (left panels) or as protein/DNA ratio (right panels). Data represent mean values from at least eight animals selected from different litters in each group at each age. SEs were $<10 \%$. For protein content, three-way ANOVA indicates a significant effect of litter size as well as interactions of litter size with all other variables. The effect on protein content was preferential for the heart (litter size $\times$ tissue interaction), but was significant both as a main effect and as an interaction with age in each individual tissue (two-way ANOVA). For protein/ DNA ratio, all tissues show statistically significant interactions of litter size $\times$ age, and except for cerebellum, a significant main effect of litter size.

\section{REFERENCES}

1. Dodge PR. Prensky AL. Feigin RD 1975 Nutrition and the Developing Nervous System. CV Mosby Company. St Louis, MO

2. Reinis S, Goldman JM 1980 The Development of the Brain: Biological and Functional Perspectives. Charles C Thomas. Springfield, IL

3. Brazier MA 1975 Growth and Development of the Brain: Nutritional Genetic and Environmental Factors, Vol I. Raven Press, New York

4. Heby O 1981 Role of polyamines in the control of cell proliferation and differentiation. Differentiation 19:1-20

5. Russell DH 1985 Ornithine decarboxylase: a key regulatory enzyme in normal and neoplastic growth. Drug Metab Rev 16:1-88

6. Slotkin TA. Bartolome J 1986 Role of ornithine decarboxylase and the poly- 
amines in nervous system development: a review. Brain Res Bull 17:307320

7. Anderson TR, Schanberg SM 1975 Effect of thyroxine and cortisol on brain ornithine decarboxylase and swimming behavior in developing rat. Biochem Pharmacol 24:495-501

8. Slotkin TA, Thadani PV 1980 Neurochemical teratology of drugs of abuse. In: Persaud TVN (ed) Advances in the Study of Birth Defects, Vol 4: Neural and Behavioral Teratology. MTP Press, Lancaster, PA, pp 199-234

9. Bell JM, Slotkin TA 1986 Polyamines as intermediates in developmental neurotoxic events. Neurotoxicology 7:147-160

10. Slotkin TA, Bartolome J 1987 Biochemical mechanisms of developmental neurotoxicity of methylmercury. Neurotoxicology 9:65-84

11. Slotkin TA, Bartolome J, Persons D, Whitmore WL 1984 Polyamines in brain and heart of the neonatal rat: effects of inhibitors of ornithine decarboxylase and spermidine synthase. Life Sci 35:1125-1131

12. Claycomb WC 1976 Biochemical aspects of cardiac muscle differentiation: possible control of deoxyribonucleic acid synthesis and cell differentiation by adrenergic innervation and cyclic adenosine $3^{\prime}: 5^{\prime}$-monophosphate. J Biol Chem 251:6082-6089

13. Altman J 1967 Autoradiographic and histological studies of postnatal kinetics, migration and transformation of cells incorporating tritiated thymidine in infant rats, with specific reference to postnatal neurogenesis in some brain regions. J Comp Neurol 128:431-434

14. Altman J, Das GD, Sudarshan K, Anderson JB 1971 The influence of nutrition on neural and behavioral development. II. Growth of body and brain in infant rats using different techniques of undernutrition. Dev Psychbiol 4:5570

15. Butler SR, Suskind MR, Schanberg SM 1978 Maternal behavior as a regulator of polyamine biosynthesis in brain and heart of developing rat pup. Science 199:445-447

16. Schanberg SM, Evoniuk G, Kuhn CM 1984 Tactile and nutritional aspects of maternal care: Specific regulators of neuroendocrine function and cellular development. Proc Soc Exp Biol Med 175:135-146

17. Lau C, Slotkin TA 1979 Regulation of rat heart ornithine decarboxylase: Changes in affinity for ornithine decarboxylase evoked by neuronal, hormonal and ontogenetic stimuli. Mol Pharmacol 16:504--512

18. Schneider W 1957 Determination of nucleic acids in tissues by pentose analysis. Methods Enzymol 3:680-684

19. Slotkin TA, Pachman S, Kavlock RJ, Bartolome J 1985 Effects of neonatal methylmercury exposure on development of nucleic acids and protein in rat brain: regional specificity. Brain Res Bull 14:397-400

20. Bell JM, Whitmore WL, Slotkin TA 1984 Effects of $\alpha$-difluoromethylornithine, a specific irreversible inhibitor of ornithine decarboxylase, on nucleic acids and protein in developing rat brain: critical perinatal periods for regional selectivity. Neuroscience 17:399-407

21. Bradford M 1976 A rapid and sensitive method for quantitation of microgram quantities of protein utilizing the principle of protein dye-binding. Anal Chem 72:248-254

22. Endo Y $1978 \mathrm{~A}$ simple and sensitive method for analysis of histamine putrescine, and polyamines without the use of an amino acid analyzer. Anal Biochem 89:235-246

23. Slotkin TA, Seidler FJ, Trepanier PA, Whitmore WL, Lerea L, Barnes GA Weigel SJ, Bartolome J 1982 Ornithine decarboxylase and polyamines in tissues of the neonatal rat: Effects of $\alpha$-difluoromethylornithine, a specific, irreversible inhibitor of ornithine decarboxylase. J Pharmacol Exp Ther 222:741-745

24. Slotkin TA, Barnes G, Lau C, Seidler FJ, Trepanier P, Weigel SJ, Whitmore WL 1982 Development of polyamine and biogenic amine systems in brains and hearts of neonatal rats given dexamethasone: Role of biochemical alterations in cellular maturation for producing deficits in ontogeny of neurotransmitter levels, uptake, storage and turnover. J Pharmacol Exp Ther 221:686-693

25. Slotkin TA, Seidler FJ, Whitmore WL, Weigel SJ, Slepetis RJ, Lerea L, Trepanier PA. Bartolome J 1983 Critical periods for the role of ornithine decarboxylase and the polyamines in growth and development of the rat: effects of exposure to $\alpha$-difluoromethylornithine during discrete prenatal or postnatal intervals. Int J Dev Neurosci 1:113-127

26. Slotkin TA, Cowdery TS, Orband L, Pachman S, Whitmore WL 1986 Effects of neonatal hypoxia on brain development in the rat: immediate and longterm biochemical alterations in discrete regions. Brain Res 374:63-74

27. Bartolome JV, Schweitzer L, Slotkin TA, Nadler JV 1985 Impaired development of cerebellar cortex in rats treated postnatally with $\alpha$-difluoromethylornithine. Neuroscience 15:203-213

28. Seiler N, Bolkenius FN 1985 Polyamine reutilization and turnover in brain Neurochem Res 10:529-544

29. Gaudreault P, Karl PI, Friedman PA 1984 Paraquat and putrescine uptake by lung slices of fetal and newborn rats. Drug Metab Dispos 12:550-552

30. Harman RJ, Shaw GG 1980 High-affinity uptake of spermine by slices of rat cerebral cortex. J Neurochem 36:1609-1615

31. Bartolome JV, Trepanier PA, Chait EA, Slotkin TA 1982 Role of polyamines in isoproterenol-induced cardiac hypertrophy: effects of a $\alpha$-difluoromethylornithine, an irreversible inhibitor of ornithine decarboxylase. J Mol Cell Cardiol 14:461-466 